UDC 616.874

\title{
EFFECT OF NORMALIZING HEATING OF FERRITE COMPACTS ON COMPACTION DURING RADIATION-THERMAL SINTERING
}

\author{
Stary O. ${ }^{1}$, Surzhikov A.P. ${ }^{2}$, Malyshev A.V. ${ }^{2^{\star}}$, Lysenko E.N. ${ }^{2}$, Sheveleva E.A. ${ }^{2}$ \\ ${ }^{1}$ Ceské vysokéucenítechnické v Prague, Prague, Czech Republic \\ 2National Research Tomsk Polytechnic University, Tomsk, Russia,malyshev@tpu.ru
}

\begin{abstract}
The study investigated linear shrinkage of lithium-titanium ferrite samples during radiation-thermal and thermal sintering. Prior to compaction, part of the powders were subjected to thermal heating for $2 \mathrm{~h}$ at temperatures of 1273, 1373, and $1473 \mathrm{~K}$. It is found that changes in the shrinkage kinetics of ferrites after powder annealing are consistent with the classical concepts of thermal deexcitation of powders due to annealing of defects. Such defects were formed in powder grains during grinding. The obtained data analysis allowed us to offer the most likely model for radiation-thermal activation of powder ferrite sintering. This is a model of radiation inhibition of non-equilibrium defects relaxation.
\end{abstract}

Keywords: ferrites, sintering, electron beams, pre-annealing of powders, linear shrinkage, shrinkage activation model.

\section{Introduction}

The effect of ionizing radiation fluxes during production and modification of materials has been employed in recent years [1-5]. Particularly interesting and fundamentally new results were obtained for objects exposed to a combined effect of powerful radiation fluxes and high temperature (the so-called radiation-thermal (RT) effect). The most important result obtained is the effect of multiple acceleration of synthesis [6-8] and sintering [9-15] of powder inorganic materials. Radiation-thermal sintering mode has been most comprehensively studied on lithium-titanium ferrites and similar structures [16-19]. These studies revealed the effect of multiple acceleration of sintering of ferrite compacts in this specific processing mode.

In $[20,21]$, a model for activation of RT sintering of ferrites based on radiation-induced diffusion (RID model) by the Deans mechanism was proposed. The authors performed a comparison with the experiment of the kinetic equation of shrinkage of ferrite compacts to confirm this model. The equations of shrinkage in turn were obtained by calculating the sintering kinetics of irradiated powder grains of arbitrary geometry.

In [22], the kinetics of compaction of lithium-titanium ferrites in thermal and radiation-thermal sintering modes was analyzed to elaborate an alternative model for RT sintering activation based on the theory of radiative deceleration of thermal heating of powder grain defects involved in mass transfer (RD model). Within the framework of this model, an active initial phase of sintering is identified with the mass transfer into the compact cavity with active involvement of intrinsic non-equilibrium defects of crystallites accumulated during synthesis and grinding of powders. Thermally-activated defect annihilation occurs simultaneously with sintering and decreases the sintering rate.

Radiation-induced point defects show a short lifetime at sintering temperature; however, they are capable of inhibiting the annealing of intrinsic defects due to distorted potential relief of crystallites. As a result, the duration of the active state of powders increases. The confirmation of both representations displays agnate deprivations change in the choice of contact geometry (RID model) and schematism of the phenomenological approach (RD model). At the identical age both representations are in arrangement with the fundamental concepts of sintering physics and radiation physics. In this regard, additional studies are required to prove the adequacy of the mechanisms of RT sintering activation.

This study presents experimental results that indicate the dominant role of the RD mechanism at early stages of isothermal sintering of ferrite compacts. The RT-sintering mechanism is confirmed based on different efficiency of the RID and RD models with the initial imperfection of powder grains. Indeed, the conditions for the RSD mechanism are most favorable in defect-free grains. On the over-the-counter give the $\mathrm{RD}$ device effectiveness is related tothe content of initial non-equilibrium defects. 
Therefore, the effect of RT sintering activation should be estimated for powders with different contents of non-equilibrium defects to reveal the dominant mechanism of radiation activation of sintering.

\section{Experimental part}

\subsection{Materials}

The samples used were lithium-titanium ferrite powders synthesized from a mechanical mixture of oxides and carbonates containing (wt.\%): $\mathrm{Li}_{2} \mathrm{CO}_{3}-11.2 ; \mathrm{TiO}_{2}-18.65 ; \mathrm{ZnO} 7.6 ; \mathrm{MnCO}_{3} 2.74$; the rest is $\mathrm{Fe}_{2} \mathrm{O}_{3}$. The samples were prepared using $10 \%$ solution of polyvinyl alcohol added to the synthesized mixture in an amount of $12 \mathrm{wt} . \%$ of the mixture. All compacts were produced in the form of pellets by cold singleaction compaction.

\subsection{Characterization techniques}

The compaction mode used was as follows: $\mathrm{P}=130 \mathrm{MPa}$, pressure holding time of 1 min. Two modes of ferrite compact sintering were used: radiation-thermal (RT- sintering) and thermal (T- sintering).For RTsintering, the samples were exposed to a pulsed electron beam with energy of (1.5-2.0) MeV using an ILU-6 accelerator. The beam current in the pulse was $(0.5-0.9)$ A, the irradiation pulse duration was $500 \mu \mathrm{s}$, the pulse repetition rate was $(5-50) \mathrm{Hz}$, and the heating rate of the samples was $1000^{\circ} \mathrm{C} / \mathrm{min}$. The samples were irradiated in a lightweight chamotte box with a wall bottom thickness of $15 \mathrm{~mm}$. On the exposed side, the box was covered with a radiation-transparent protector with a mass thickness of $0.1 \mathrm{~g} \cdot \mathrm{cm}^{-1}$. The temperature was measured using a control sample placed in close proximity to the sintered samples.

$\mathrm{T}$-sintering was performed in a preheated electric chamber furnace to ensure a heating rate comparable to the radiation heating rate. The cell design and the temperature control technique are similar to those used for RT sintering. Sintering in both modes was performed in air.

The electrical resistivity of ferrites was measured at direct current based on a two-electrode scheme on pellet-shaped samples with a near-electrode layer of soft graphite. The measurements were performed during heating from room temperature to $1300 \mathrm{~K}$. The air pressure in the measuring cell did not exceed $19 \mathrm{~Pa}$, the heating rate of samples was 10 degrees per minute. The electric field applied to the sample was $10 \mathrm{~V} / \mathrm{cm}$.

Prior to compaction, powders were subjected to thermal heating to control pre-radiation nonequilibrium defect structure. Normalizing warming was performed for $2 \mathrm{~h}$ in a resistance furnace at 1273 , 1373 , and $1473 \mathrm{~K}$. Upon culmination of heating, dusts were slowly cooled to room temperature, and after the addition of a binding additive, pellets $15.1 \mathrm{~mm}$ in diameter and $15.0 \mathrm{~mm}$ thick were compacted. The shrinkage of samples after sintering was determined by measuring the geometric dimensions L.

\section{Results and discussion}

Figure 1a presents the results that show the effect of normalizing heating of powders on the sintering kinetics in the electron beam radiation mode. Samples sintered in the T mode show similar dependences (Fig. 1b). Changes in the shrinkage kinetics of ferrites after annealing of compacts are in estimable conformity with the definitive concepts of thermal dismissal of dusts due care to annealing of grindinginduced shortcomings in powder grain [23]. The changes ascertained do not depend on the sintering mood. These points out a similar attribute of the mass transferee devices in both fashions. For quantitative judgement of the effect of compaction activation during RT-sintering at the initial positions of isothermal sintering, the value of the relative shrinkage of compacts for a fixed sintering time can be used (Fig. 1).

Comparison of $\Delta L / L_{\mathrm{PT}}$ with a similar value $\Delta L / L_{\mathrm{T}}$ obtained in $\mathrm{T}$ sintering can help reveal the effect of preheating of powders on the RT activation effect. Table 1 shows the comparison results for the sintering parameters: $T=1370 \mathrm{~K}, \tau_{\mathrm{c}}=15 \mathrm{~min}$.

Table 1.Effect of compact heating on the relative efficiency $(Z)$ of isothermal RT-sintering

\begin{tabular}{|c|c|c|c|c|}
\hline$T_{\text {heating }}, \mathrm{K}$ & Initial powder & 1273 & 1373 & 1473 \\
\hline$Z, \%$ & 90 & 19 & 11 & 0 \\
\hline
\end{tabular}




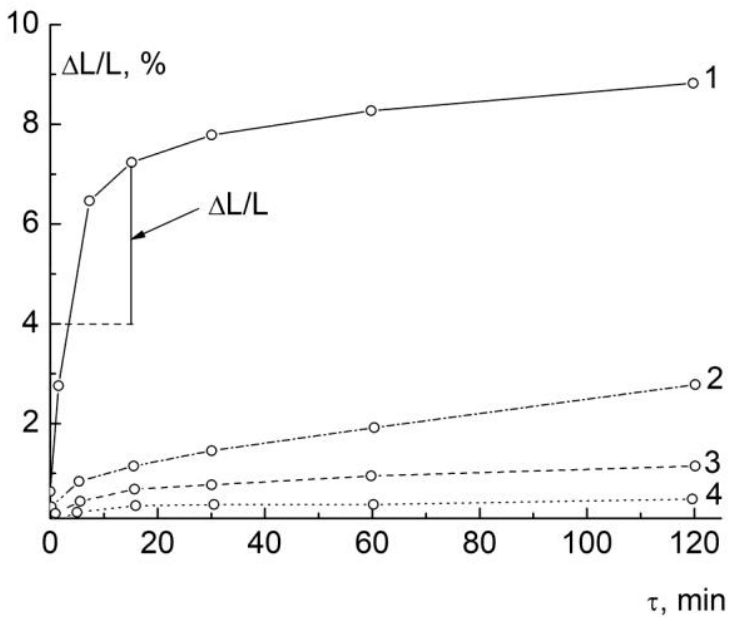

a)

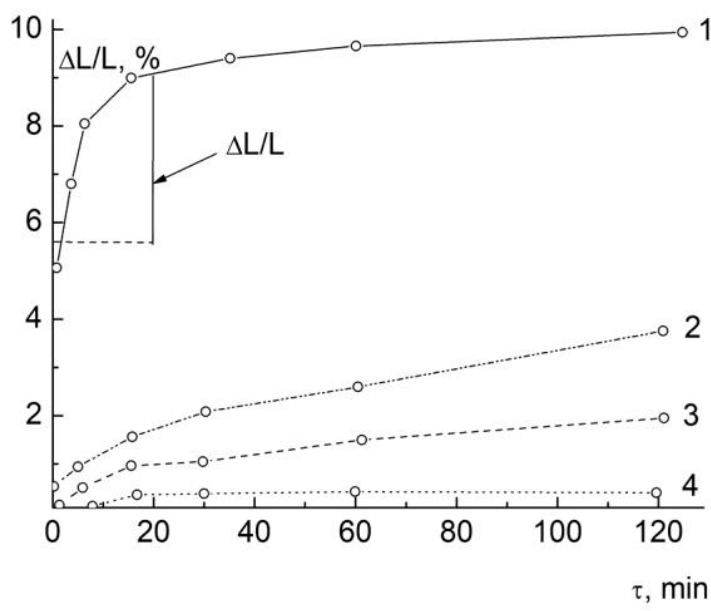

b)

Fig.1. Kinetic patterns of linear shrinkage of ferrites: RT-sintering (a); T-sintering at $1373 \mathrm{~K}$ (b). The powder was heated before compaction for $1 \mathrm{~h}$ at $1273 \mathrm{~K}(2), 1373 \mathrm{~K}(3), 1473 \mathrm{~K}$ (4); non-heated powder (1).

The relative efficiency of isothermal RT-sintering (Z) was calculated according to (1) [24].

$$
Z=\frac{\Delta L / L_{R T}-\Delta L / L_{T}}{\Delta L / L_{T}}
$$

Data in Table 1 show that the RT-sintering rate almost twofold exceeds the T sintering grade (in original powders); nevertheless it sharply diminishes abaft preheating of dusts When the warming temperature surpasses the sintering temperature, the compaction effectiveness regularizes $(\mathrm{Z}=0)$. That is, the radiation core all vanishes in ferrite dusts deactivated at temperature like to the sintering temperature. This points out that the modeling for dispersal prohibition of non-equilibrium desert leisure is the near most likely device for activation of RT sintering of ferrite dusts.

\section{Conclusion}

The scientific value of the research is determined by the model of radiation prohibition of nonequilibrium desert leisure for activation of RT sintering of ferrite powders. Sintering of ferrite powders at yearly stages proceeds by the mechanism of threshold dislocation creep. In this case the activating role of radiation is due to the inhibition of dislocation defect annealing. At later sintering stages, dominate mechanisms of volumetric self-diffusion. Emphasize, the radiation effects manifested by the model of radiation-stimulated diffusion is supposed to occur at these stages only.

\section{Acknowledgments}

The research is funded by the Ministry of Education and Science of the Russian Federation as part of the "Science" Program (project No. FSWW-2020-0014). This research was supported by TPU development program.

\section{REFERENCES}

1 Groom D.E., Klein S.R. Review of Particle Physics. European Physical Journal C. 1998, Vol.3, pp. 144 - 151.

2 Sagynganova I.K., Markin V.B. The organizations of the tasks implementation in the distributed automatic control systems of heat supply stations. News of the National Academy of Sciences of the Republic of Kazakhstan. 2019, Vol. 1, No. 433, pp. $63-67$.

3 Ershov B.G. Radiation technologies: their possibilities, state, and prospects of application. Herald of the Russian Academy of Sciences. 2013, Vol. 83, No. 5, pp. 437 - 447.

4 Obodovskiy I. Radiation: fundamentals, applications, risks, and safety. Elsevier Inc., 2019, 694p. https://doi.org/10.1016/C2014-0-00520-5

5 Yurov V.M., Baltabekov A.S., Laurinas V.C., Guchenko S.A. Dimensional effects and surface energy of ferroelectric crystals. Eurasian phys. tech. j. 2019, Vol. 16, No. 1(31), pp. 18 - 23. doi 10.31489/2019No1/18-23 
6 Sharma P. Uniyal, Investigating thermal and kinetic parameters of lithium titanate formation by solid-state method, J. Therm. Anal. Calorim. 2017, Vol. 128, pp. 875 - 882.

7 Rakshit S.K., Parida S.C., Naik Y.P., Venugopal V. Thermodynamic studies on lithium ferrites, J. Solid State Chem. 2011, Vol. 184, pp. 1186 - 1194.

8 Boldyrev V.V., Voronin A.P., Gribkov O.S., Tkachenko E.V., Karagedov G.R., Yakobson B.I., Auslender V.L. Radiation-thermal synthesis. Current achievement and outlook, J. Solid State Ion. 1989, Vol. 36, pp. 1 - 6.

9 Lyakhov N.Z., Boldyrev V.V., Voronin A.P., Gribkov O.S., Bochkarev I.G., Rusakov S.V., Auslender V.L. Electron beam stimulated chemical reaction in solids. J. Therm. Anal. Calorim. 1995, Vol. 43, pp. 21 - 31. https://doi.org/10.1007/BF02635965.

10 Halamani Koushallya M., Mathad Shalini K., Kulkarni Akshay B., Mathad Shridhar N., et al. Variation of structural properties of al doped ni-cd ferrites with sintering time. Eurasian Physical Technical Journal.2020, Vol. 17, No.2 (34), pp. $11-18$.

11 Kostishyn V.G., Komlev A.S., Korobeynikov M.V., Bryazgin A.A., Shvedunov V.I., Timofeev A.V., Mikhailenko M.A. Effect of a temperature mode of radiation-thermal sintering the structure and magnetic properties of Mn-Zn-ferrites. Journal of Nano- and Electronic Physics. 2015, Vol. 7, pp. 04044.

12 Stary O., Malyshev A.V., Lysenko E.N., Petrova A. Formation of magnetic properties of ferrites during radiation-thermal sintering. Eurasian Physical Technical Journal.2020, Vol. 17, No. 2(34). pp. 6 - 10. doi 10.31489/2020No2/6-10.

13 Nikolaev E.V., Astafyev A.L., Nikolaeva S.A., Lysenko E.N., Zeinidenov A.K. Investigation of electrical properties homogeneity of li-ti-zn ferrite ceramics. Eurasian Physical Technical Journal. 2020, Vol. 17, No.1(33), pp. 5 -12 .

14 Sharipov M.Z., Hayitov D.E., Rizoqulov M.N., Islomov U.N., Raupova I.B. Domain structure and magnetic properties of terbium ferrite-garnet in the vicinity of the magnetic compensation point. Eurasian Physical Technical Journal.2019, Vol. 16, No. 2(32). pp. $21-25$.

15 Mehnert R. Review of industrial applications of electron accelerators. Nuclear Instruments and Methods in Physics Research Section B: Beam Interactions with Materials and Atoms. 1996, Vol. 113, pp. 81 - 87. https://doi.org/10.1016/0168-583X(95)01344-X.

16 Martins M.N., Silva T.F. Electron accelerators: History, applications, and perspectives. Radiation Physics and Chemistry. 2014, Vol. 95, pp. 78 - 85. https://doi.org/10.1016/j.radphyschem.2012.12.008.

17 Surzhikov A.P., Frangulyan T.S., Ghyngazov S.A. A thermoanalysis of phase transformations and linear shrinkage kinetics of ceramics made from ultrafine plasmochemical $\mathrm{ZrO}_{2}(\mathrm{Y})-\mathrm{Al}_{2} \mathrm{O}_{3}$ powders. Journal of Thermal Analysis and Calorimetry.2014, Vol. 115, No. 2, pp. $1439-1445$.

18 Surzhikov A.P., Pritulov A.M., Lysenko E.N., Sokolovskiy A.N., Vlasov V.A., Vasendina E.A. Calorimetric investigation of radiation-thermal synthesized lithium pentaferrite. J. Therm. Anal. Calorim. 2010, Vol. 101, No. 1, pp. $11-13$.

19 Surzhikov A.P., Pritulov A.M., Lysenko E.N., et al. Influence of solid-phase ferritization method on phase composition of lithium-zinc ferrites with various concentration of zinc. J. Therm. Anal. Calorim. 2012, Vol. 109, No. 1, pp. $63-67$.

20 Surzhikov A.P., Lysenko E.N., Vlasov V.A., Malyshev A.V., Nikolaev E.V. Investigation of the process of ferrite formation in the $\mathrm{Li}_{2} \mathrm{CO}_{3}-\mathrm{ZnO}-\mathrm{Fe}_{2} \mathrm{O}_{3}$ system under high-energy. Russian Physics Journal. 2013, Vol. 56, No. 6, pp. $681-685$.

21 Grishaev V.V., Lebed' B.M. About mechanism of electron-thermal sintering of ferrites. Electronic equipment. Ser. Materials. 1985, No. 1, pp. 18 - 24. [in Russian]

22 Smith J., Wijn H.P.J. Ferrites: Physical properties of ferromagnetic oxides in relation to their technical application. Eindhoven, Phillips Technical Library, 1959, 233p.

23 Neronov V.A., Voronin A.P., Tatarintseva M.I., et al. Sintering under a high-power electron beam. Journal of the Less Common Metals. 1986, Vol. 117, pp. 391 - 394. https://doi.org/10.1016/0022-5088(86)90065-2

24 Geguzin J.E. Physics of Sintering.1984, Moscow, Nauka, 360 p. 